\title{
To Study the maternal factors which determine the low birth weight babies?
}

\author{
Agarwal A $\mathbf{1}^{1}$, Sharma $\mathbf{V}^{2}$ \\ ${ }^{1}$ Dr Astha Agrawal, Associate Professor, Department of Pediatrics, Shridev Suman Subharti Medical College, Dehradun, \\ India, ${ }^{2}$ Dr Varuni Sharma, Assistant Professor, Department of Obstetrics \& Gynecology, Shridev Suman Subharti Medical \\ College, Dehradun, India.
}

Address for Correspondence: Dr Astha Agrawal, Email: drasthaagrawal@gmail.com

\begin{abstract}
Introduction: Birth weight is an important determinant of child survival and development. LBW is closely associated with fetal and perinatal mortality and morbidity. This study was conducted to know the maternal and biosocial factors that influence low birth weight babies. Material Methods: A case control study carried out with, 500 neonates were selected randomly for the study in which 250 who were LBW babies $(<2500 \mathrm{gm})$ were labeled as cases \& 250 equally matched normal birth weight $(<2500 \mathrm{gm})$ were served as control. The variables were subjected to computer analysis using focus format. The data was analysed using a ChiSquare for quantitative data. Chi square test was used to calculate $\mathrm{p}$ value. $\mathrm{P}$ value was considered significant if $<0.05$ SPSS version 16 software is used to do the necessary statistical calculations. Results: maximum number that is $41 \%$ of babies were low birth weight with female predominance while male predominance in normal birth weight, maximum number of low birthweight babies were preterm (74.24\%) followed by full term \& post term, low birth weight babies with increasing frequency was found among mothers below 20 years age group and more than 35 years age group, undernourished mother $(<50 \mathrm{~kg})$ and short stature mothers and mother with low socio economic status. Conclusion: The prevalence of low birth weight was found to be higher and it was associated with young mother, short stature, gestational age $<37 \mathrm{wks}$, presence of any chronic medical illness, maternal weight $<50 \mathrm{~kg}$. and short stature. Emphasis should be given to nutritional counseling and disease specific ANC provision by skilled health professionals; Discussions with the community and religious leaders are mandatory aspect on the tradition of feeding of pregnant mothers to tackle the problem. This study also calls for community based further studies.
\end{abstract}

Keywords: Low birth weight, Maternal height, maternal lweight, socioeconomic status.

\section{Introduction}

The World health organization (WHO) defined low birth weight $(\mathrm{LBW})$ as weight at birth of less than 2,500 grams. This practical cut-off for international comparison is based on epidemiological observations that infants weighing less than 2,500 grams are approximately 20 times more likely to die than heavier babies [1]. The prevalence of LBW in any population reflects its socio-economic development and it is a good proxy to gauge the developmental status of the country [2]. Low birth weight is associated with many socioeconomic factors such as residence (urban-rural difference), mother's age and occupation, birth order, the family's income and many maternal conditions such

Manuscript received: $16^{\text {th }}$ December 2016

Reviewed: $24^{\text {th }}$ December 2016

Author Corrected: $2^{\text {nd }}$ January 2017

Accepted for Publication: $11^{\text {th }}$ January 2017 as nutritional status, mother's educational and health status [3]. Known factors for pre-term delivery and fetal growth retardation which are associated with LBW include low maternal food intake and illness, especially infections. Studies suggest that short maternal stature, very young age, high parity, close birth spacing were all associated factors $[4,5]$.

Many socio-biological factors have been postulated to determine the birth weight of the newborn. The principal among these are maternal age, weight, height, education, parity, antenatal care, maternal smoking, and sex of the baby. In addition, LBW has a higher association with the incidence of infection, malnutrition and handicapping conditions during childhood [6]. In developing countries, many women are short and underweight and the number of low birth weight (LBW) babies is particularly high 
(more than 30\% in South Asia, 10-20\% in other regions. of survival; LBW babies have less chances of survival, when they do survive, they are more prone to disease, growth retardation and impaired mental development[7].

A good start in life is important and maternal nutritional status during pregnancy has repeatedly been demonstrated to be associated with pregnancy outcomes for the infant. Keeping all these in views, an attempt has been made to carry out a study on LBW babies at our institution.

\section{Material \& Methods}

The present entitled retrospective study of determinates of low birth weight babies was carried out in the department of Pediatrics, Gandhi Medical College, Kamla Nehru Hospital, Bhopal.

Total of 500 neonates were selected randomly for the study in which 250 who were LBW babies $(<2500 \mathrm{gm})$ were labeled as cases \& 250 equally matched normal birth weight $(<2500 \mathrm{gm})$ were served as control.

The cases \& control were taken from the Department, GMC, Bhopal who were referred here form Sultania Zanana Hospital and other hospitals of Bhopal \& near by home deliveries.

\section{Inclusion criteria}

1. Live birth babies

2. Singleton babies

\section{Exclusion criteria-}

1. Still births

2. Twin gestation

3. Babies with major congenital anomalies
Method of Study- In this study, an analysis 150 mothers of LBW babies was done and compared with 300 normal weight babies. The variables were subjected to computer analysis using focus format.

The data was analysed using a Chi-Square for quantitative data. Chi square test was used to calculate $p$ value. $P$ value was considered significant if $<0.05$ SPSS version 16 software is used to do the necessary statistical calculations.

The first weight of the new born was obtained after birth. The weight was measured preferably within the first hour of life before significant postnatal loss of weight has occurred. Birth weight measurements were compared to measurements within 24 hours of birth.

Heavy objects like metal forceps, for occluding umbilical cord were omitted. Weight scales were checked at intervals for accuracy.

The details of mothers who had delivered infants within the last 24 hours below 2500 grams were taken from the labour room and postnatal ward. The neonates were weighed naked within 24 hours after birth in a spring-dial baby weighing machine with sensitivity of 20 grams and graded up to $41 / 2 \mathrm{kgs}$ in 20 gram units. Sex of the baby was noted. Any congenital malformation was ruled out.

Sampling mothers- The same procedure used above for locating the infants was also used to trace the mother. Age, weight, parity, height, literacy level, total family income and maternal diseases during antenatal period were enquired by questionnaire method.

Statistical Analysis- Statistical analysis was done by calculation of range, median, mean, standard deviation, percentage, odds ratio, chi square test and $\mathrm{p}$ value.

\section{Results}

Table No 1: Comparison of maturity of babies.

\begin{tabular}{|c|c|c|c|c|c|}
\hline \multirow{2}{*}{ Maturity } & \multicolumn{2}{|c|}{ LBW } & \multicolumn{2}{c|}{ NBW } & Total \\
\cline { 2 - 5 } & No. & $\%$ & No. & $\%$ & 264 \\
\hline Preterm & 196 & 74.24 & 68 & 25.76 & 230 \\
\hline Full term & 52 & 22.60 & 178 & 77.4 .67 & 6 \\
\hline Post term & 2 & 33.33 & 4 & $\mathbf{2 5 0}$ & $\mathbf{5 0 0}$ \\
\hline Total & $\mathbf{2 5 0}$ & & & & \\
\hline
\end{tabular}


Table No. 1 shows that maximum number of low birth weight babies are preterm followed by full term \& post term while the maximum no of normal birth weight babies are full-term followed by preterm $\&$ then post term.

Table No 2: Distribution of Newborn by Birth Weight.

\begin{tabular}{|c|c|c|}
\hline Birth Weight & Number & \%age \\
\hline$<1 \mathrm{~kg}$ & 7 & 1.4 \\
$1-1.49 \mathrm{~kg}$ & 95 & 19 \\
$1.5-2.49 \mathrm{~kg}$ & 148 & 30 \\
$2.5-3.49 \mathrm{~kg}$ & 203 & 41 \\
$3.4-4 \mathrm{~kg}$ & 43 & 8.6 \\
$>4 \mathrm{~kg}$ & 4 & 0.8 \\
\hline
\end{tabular}

Table No. 2 shows most of the newborns are having birth weight $(2.5-3.49 \mathrm{~kg})$ that is $41 \%$.

Table No.-3: Distribution of birth weight by sex.

\begin{tabular}{|c|c|c|c|c|c|}
\hline \multirow{2}{*}{ Sex } & \multicolumn{2}{|c|}{ LBW } & \multicolumn{2}{|c|}{ NBW } & \multirow{2}{*}{ Total } \\
\cline { 2 - 5 } & No. & $\%$ & No. & $\%$ & \\
\hline Male & 116 & 37.5 & 194 & 62.5 & 310 \\
Female & 134 & 70.5 & 56 & 29.5 & 190 \\
\hline
\end{tabular}

These table show predominance of male sex among normal birth weight babies while female were predominate in low weight category.

Table No. 4: Relationship between maternal age $\&$ birth weight.

\begin{tabular}{|c|c|c|c|c|c|}
\hline \multirow{2}{*}{$\begin{array}{c}\text { Age of Mother } \\
\text { (yr.) }\end{array}$} & No. & \% & No. & Total \\
\cline { 2 - 5 } & 80 & 57.14 & 60 & 42.86 & \\
\hline $20 \mathrm{yr}$ & 122 & 45.18 & 148 & 54.82 & 270 \\
$20-34 \mathrm{yr}$ & 48 & 53.34 & 42 & 46.66 & 90 \\
$>35 \mathrm{yr}$. & & & & \\
\hline
\end{tabular}

Above table shows that increasing frequency of low birth weight babies is found among mothers below 20 years age group and more than 35 years age group.

Table No. 5: Relationship between maternal weight \& birth weight.

\begin{tabular}{|c|c|c|c|c|c|}
\hline \multirow{2}{*}{$\begin{array}{c}\text { Maternal } \\
\text { weight }\end{array}$} & No. & \% & No. & Total \\
\cline { 2 - 5 } & $<50 \mathrm{~kg}$ & 70.2 & 65 & 29.8 & \\
$>50 \mathrm{~kg}$ & 153 & 34.4 & 185 & 65.6 & 218 \\
\hline
\end{tabular}

Table 5 shows maternal weight $<50 \mathrm{~kg}$ is highly associated with low birth weight babies.

Table-6: Relationship between maternal height \& birth weight.

\begin{tabular}{|c|c|c|c|}
\hline Mother height & LBW & NBW & TOTAL \\
\hline$<145 \mathrm{~cm}$ & 117 & 16 & 133 \\
& $46.7 \%$ & $6 \%$ & 211 \\
\hline $145-154$ & 111 & 100 & 156 \\
\hline
\end{tabular}


Above table shows those maximum numbers of low birth weight babies are delivered from short statured mother (height $<$ $145 \mathrm{~cm})$.

Table No.7: Relationship between Maternal Socioeconomic Status \& Birth Weight.

\begin{tabular}{|c|c|c|c|}
\hline Socioeconomic status & LBW & NBW & TOTAL \\
\hline I & 3 & 9 & 12 \\
\hline II & $1.3 \%$ & $4.3 \%$ & 105 \\
\hline III & 21 & 84 & 278 \\
& $8.7 \%$ & $34.7 \%$ & 78 \\
\hline IV & 138 & $56.3 \%$ & 28 \\
\hline V & $55.7 \%$ & 140 & \\
\hline
\end{tabular}

Above table shows that Socioeconomic class is divided into 5 classes according to Kuppuswamy classification: I,II,III,IV,V. 54.7\% of mothers who had LBW baby belonged to class III. There is a higher statistical significance between birth weight and socioeconomic class.

\section{Discussion}

This study was undertaken to study the influence of maternal factors in low birth weight babies. In our study we found that increasing frequency of low birth weight babies is found among mothers below 20 years age group and more than 35 years age group, this is similar to the study done by Parlington [8] and Tabcharoen [9].

In a cross-sectional observational study[10] done on teenage primigravida mothers in a tertiary care hospital in eastern India showed that the teenage mothers had a higher proportion $(27.7 \%)$ of preterm deliveries compared to $13.1 \%$ in the adult mothers and had lowbirthweight babies (38.9\% vs. $30.4 \%$, respectively).

Roth et al [11] investigated the incidence of LBW among adolescent mothers in United State of America and gave explanation for the young maternal age - low birth weight gradient, that is, the lower the mother's age, the higher the risk of having LBW baby.

In his study, the percentage of LBW babies was highest among mothers with age less than 15 years, that is, 13.7 percent and those mothers with age $15,16,17,18$, and 19, the percentage of LBW babies was 11.5, 10.3, 9.6, 9.1, and 8.6, respectively. There is a higher statistical signifance when the maternal weight is compared to birth weight ( $p<50 \mathrm{~kg}$, low birth weight incidence is $59.3 \%$, while the incidence in those weighing $>50 \mathrm{~kg}$ is $40.6 \%$. This is similar to the studies done by Srinivas Prudhivi
[12] and Aras et al [13]. There is higher significant association between height and low birth weight babies, Our study showed that maximum number of low birth weight babies are delivered from short statured mother (height $<145 \mathrm{~cm}$ ). This is similar to the studies done by S. Ganesh kumar [14].

Socioeconomic class is divided into 5 classes according to Kuppuswamy classification: I (upper), II (upper middle), III (lower middle), IV (lower middle), V (lower). $54.7 \%$ of mothers who had LBW baby belonged to class III. There is a higher statistical significance between birth weight and socioeconomic class. This is similar to the studies $[6,15]$.

The case-control study of 673 term LBW, 644 preterm LBW cases and 1465 controls showed that low maternal weight, poor obstetric history, lack of antenatal care, clinical anaemia and hypertension were significant independent risk factors for both term and preterm LBW. Short interpregnancy interval was associated with an increased risk of preterm LBW birth while primiparous women had increased risk of term LBW.

Muslim women were at a reduced risk of term LBW, but other socioeconomic factors did not remain significant after adjusting for these more proximate factors. Estimates of the prevalence of risk factors from the population survey were used to calculate attributable 
risk. This analysis suggested that a substantial proportion of term and preterm LBW births may be averted by improving maternal nutritional status, anaemia and antenatal care [16].

There is a significant association between maternal risk factors like Oligohydramnious, PIH (pregnancy induced hypertension), and birth weight. Among the mothers who have delivered LBW babies, about $25 \%$ had oligohydramnious, $14 \%$ had PIH. p value is significant especially with the group having oligohydramnious. The incidence of APH (antepartum hemorrhage) and PROM (premature rupture of membranes) is comparatively on the higher side among the controls. Studies done by AM Mark Anez Conteras and LR Rahman also showed that $\mathrm{PIH}$ is a risk factor for LBW $[17,18]$.

\section{Conclusion}

This study was conducted to know the maternal and biosocial factors that influence low birth weight babies. it has concluded LBW was found to be affected by maternal age, maternal weight $<50 \mathrm{~kg}$, maternal height $<145 \mathrm{~cm}$, low socio economic status and presence of any chronic medical illnesses. Many risks for LBW can be identified before pregnancy occurs. Health education, socioeconomic development, maternal nutrition, and increasing the use of health services during pregnancy, are all important for reducing LBW.The problem of LBW in India needs focused attention, and research requires innovative strategies to attempt to identify protective factors among women who are at high risk.

Funding: Nil, Conflict of interest: None initiated, Perission from IRB: Yes

\section{Bibliography}

1. United Nations Children's Fund and WHO: Low Birth Weight country, regional and global estimates. New York; 2004.available from [http://www.unicef.org/ publications / index_24840. html]. Last accessed 24 May 2013.

2. Taylor HG, Minich NM, Klein N, Hack M. Longitudinal outcomes of very low birth weight: neuropsychological findings. J Int Neuropsychol Soc. 2004 Mar; 10(2):149-63.

3. Siza JE. Risk factors associated with low birth weight of neonates among pregnant women attending a referral hospital in northern. Tanzan J Health Res. 2008; 10:1-8.
4. Rajaeefard A, Mohammadi M, Choobineh A. Preterm delivery risk factor: a prevention strategy in Shiraz, Islamic Republic of Iran. East Mediterr Health J. 2007;13:17.

5. Zeleke BM, Zelalem M, Mohammed N. Incidence and correlates of low birth weight at a referral hospital in Northwest Ethiopia. Pan Afr Med J. 2012;12:4. Epub 2012 May 4.

6. Dunin-Wasowicz D, Rowecka-Trzebicka K, Milewska-Bobula B, Kassur-Siemieńska B, Bauer A, Idzik M, Lipka B, Marciński P. Risk factors for cerebral palsy in very low-birthweight infants in the 1980s and 1990s. J Child Neurol. 2000 Jun;15(6):417-20.

7. Dharmalingam A, Navaneetham K, Krishnakumar CS. Nutritional status of mothers and low birth weight in India. Matern Child Health J. 2010 Mar;14(2):290-8. doi: 10.1007/s10995-009-0451-8. Epub 2009 Feb 7.

8. Partington SN, Steber DL, Blair KA, Cisler RA. Second births to teenage mothers: risk factors for low birth weight and preterm birth. Perspect Sex Reprod Health. 2009 Jun;41(2):101-9. doi: 10.1363/4110109.

9. Tabcharoen C, Pinjaroen S, Suwanrath C, Krisanapan O. Pregnancy outcome after age 40 and risk of low birth weight. J Obstet Gynaecol. 2009 Jul;29(5):378-83. doi: $10.1080 / 01443610902929537$.

10. Mukhopadhyay P, Chaudhuri RN, Paul B. Hospitalbased Perinatal Outcomes and Complications in Teenage Pregnancy in India. J Health Popul Nutr 2010; 28:494500 .

11. Roth J, Hendrickson J, Schilling M, Stowell DW. The Risk of Teen Mothers Having Low Birth Weight Babies: Implications of Recent Medical Research for School Health Personnel. J Sch Health 1998;68:271-5.

12. Prudhivi $\mathrm{S}$ et al. Maternal factors influencing low birth weight babies. Int J Contemp Pediatr. 2015 Nov;2 (4):287-296.

13. Radha Y. Aras Is maternal age risk factor for low birth weight? Archives of Medicine and Health Sciences Jan-Jun 2013 / Vol 1 | Issue 1. http://www. amhsjournal.org

14. Ganesh Kumar S, Harsha Kumar HN, Jayaram S, Kotian MS. Determinants of low birth weight: a case control study in a district hospital in Karnataka. Indian J 
Pediatr. 2010 Jan;77(1):87-9. doi: 10.1007/s12098-0090269-9.

15. Hirve SS, Ganatra BR. Determinants of low birth weight: a community based prospective cohort study. Indian Pediatr. 1994 Oct; 31(10):1221-5.

16. Mavalankar DV, Gray RH, Trivedi CR. Risk factors for preterm and term low birthweight in Ahmedabad, India. Int J Epidemiol. 1992 Apr;21(2):263-72.
17. Martínez Contreras AM, Soria Rodríguez CG, Prince Vélez R, Clark Ordoñez I, Medina Ramírez MC. [Preeclampsia: main maternal risk factor for low weight in preterm newborn]. Ginecol Obstet Mex. 2008 Jul; 76(7):398-403.

18. Rahman LA. Association between pregnancy induced hypertension and low birthweight; a population based case-control study. Asia Pacific Journal of Public Health. 2008;20(2):152-8.

\section{How to cite this article?}

Agarwal A, Sharma V. To Study the maternal factors which determine the low birth weight babies? J PediatrRes.2017;4(01):6-11.doi:10.17511/ijpr.2017.i01.02 